\title{
Spotfire Utilisation Project: Development of a mapping tool for regions prone to vorticity-driven lateral spread
}

\author{
$\underline{\text { R.L. Badlan }}^{\mathrm{a}}$ (i) and J.J. Sharples ${ }^{\mathrm{a}} \mathrm{b} \mathrm{c}$ \\ a School of Science, University of New South Wales, Canberra, ACT 2600, Australia. \\ ${ }^{\mathrm{b}}$ Bushfire and Natural Hazards Cooperative Research Centre, East Melbourne, Vic. 3002, Australia. \\ ${ }^{\mathrm{c}}$ ARC Centre of Excellence for Climate Extremes, UNSW Canberra, ACT 2600, Australia \\ Email: $\underline{\text { r.badlan@adfa.edu.au }}$
}

\begin{abstract}
Extreme wildfire development begins when a small fire transitions to a larger fire whch may then escalate to a mass or areal fire. One such trigger for this dynamic fire spread is a phenomenon known as vorticity-driven lateral spread (VLS), whereby the fire spreads laterally along ridgelines. Prediction of such events can be improved using a wind-terrain filter. This filter is a tool to aid in the identification of regions of the landscape that are prone to mass spotting and other dynamic fire behaviours associated with VLS. It is designed to be used by Fire Behaviour Analysts (FBANs) who may then use the information to influence decision-making when deploying resources and personnel.

Findings from previous research, which identified conditions that are conducive to VLS, were then used to create a mapping overlay identifying where slopes are sufficiently steep and the ridgelines orientated in a particular direction. However, as the distributions of slope vary with the resolution of the digital elevation model (DEM), the relationship between resolution and slope threshold was first determined.

The filter uses both the first- and second-order directional derivatives (slope and curvature respectively). The first-order and second-order wind-terrain filter enables the user to identify parts of the terrain which are sus-ceptible to VLS through its established association with steep or broken leeward-facing terrain elements. This is achieved using terrain attributes such as topographic slope, aspect, and profile curvature, as well as environ-mental variables such as the wind speed and direction.

This mapping tool is then applied to a case study from 2020 that took place in Montana, USA. Using the forecast data, the VLS filter was applied to the initial fire perimeter to to determine whether it highlighted areas where lateral spread occurred. The filter correctly identified VLS areas and, when interpreted with the forecast wind and those regions at risk, clearly indicated the approximate direction and the final burn area of the fire.
\end{abstract}

Keywords: Spotfires, dynamic fire behaviour, GIS, digital elevation models, extreme fires 
R.L. Badlan and J.J. Sharples, Spotfire Utilisation Project: Development of a mapping tool...

\section{INTRODUCTION}

An extreme bushfire is the most dangerous manifestation of a fire and is defined as "a fire that exhibits deep or widespread flaming in an atmospheric environment conducive to the development of violent pyroconvection, which manifests as towering pyrocumulus (pyroCu) or pyrocumulonimbus (pyroCb) storms" (Sharples et al. 2016). These fires are increasingly in frequency and intensity due to changing conditions such as increased drought and global temperatures. The challenge is to easily identify the conditions that enable wildfires to transition from relatively benign to extreme.

\section{Triggers of extreme fires}

The development of such fires is driven by a number of factors that can cause small fires to rapidly escalate in size and intensity. Extreme fires exhibit expansive areas of active flaming - referred to as 'deep flaming' (McRae et al. 2015). Fires that have regions of deep flaming have also been referred to by other authors as 'areal fires' or 'mass fires'.

Factors that may act as triggers for extreme fires include: change of wind direction, strong winds, eruptive fire behaviour, mass-spotting and fire coalescence, and VLS (Badlan et al. 2021 a b). The last three of these involve dynamic fire propagation, whereby the fire spread transitions from a quasi-steady to an accelerated rate of spread. Dynamic fire behavours are problematic not only because the fires increase their size rapidly, but they may also catch people in the vicinity offguard, leading to loss of life and property. VLS has been identified as a driver of extreme fire development in numerous events such as the 2003 Canberra fires (McRae 2004 Sharples et al. 2012. Simpson et al. 2015), and the Aberfeldy (Quill \& Sharples 2015) and the Wambelong fires of 2013 (Dillon 2015).

\section{Vorticity-driven lateral spread (VLS)}

VLS occurs when steep (or broken) topography and strong winds interact to produce flow separation, creating horizontal vorticity such as a lee slope eddy (Fig. 1). The fire's updraft may then stretch and tilt this horizontal vorticity into intense vertical vorticity, which may then cause the fire to spread laterally along the ridge line (Simpson et al. 2014). As lateral spread is associated with intense vorticity, this means that ember generarion is enhanced. These embers are then transported laterally and downwind due to the combined influence of the vertical vorticity and the prevailing wind, potentially resulting in mass spotting and fire coalescence (Sharples et al. 2020).

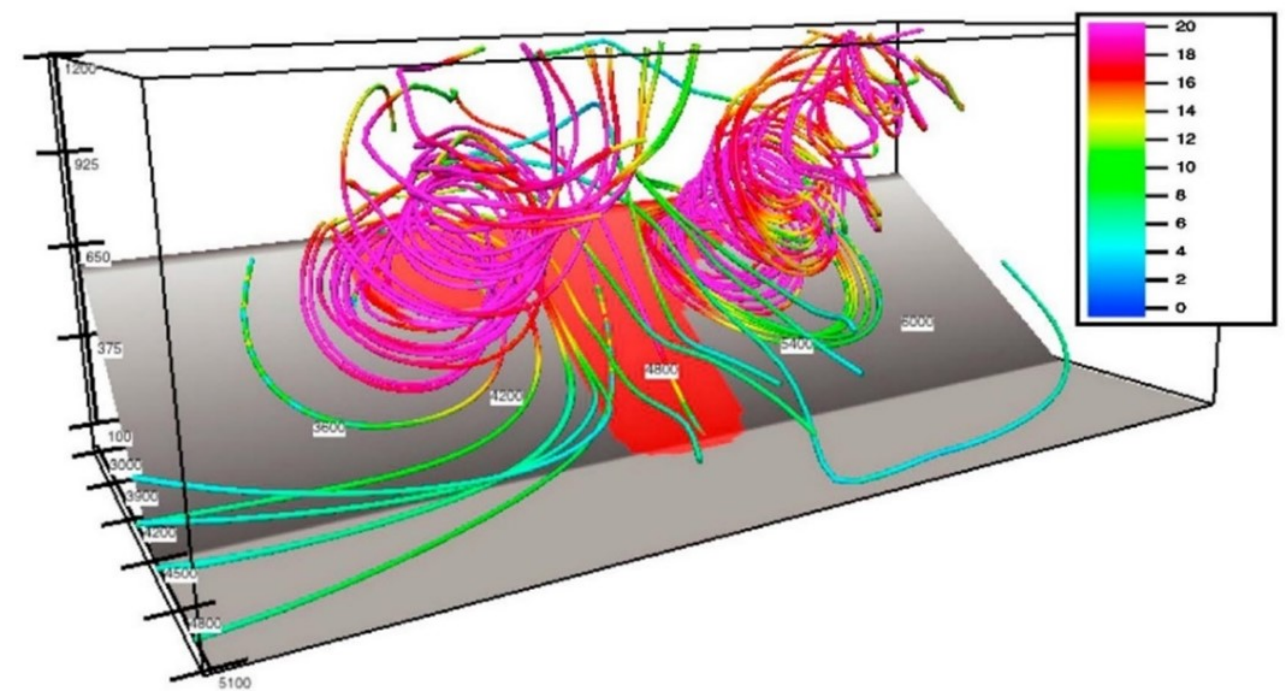

Figure 1. Simulation of VLS across leeward slope, with lines representing the streamlines in $\mathrm{m} \mathrm{s}^{-1}$. Red shading represents the extent of the fire area. Wind is aligned perpendicular to the ridge axis. (Simpson et al. 2016) 
R.L. Badlan and J.J. Sharples, Spotfire Utilisation Project: Development of a mapping tool...

\section{VLS filter}

Early work by Sharples et al. (2012) established wind and terrain conditions that are necessary (but not sufficient) for VLS occurrence. These conditions relate to the likelihood of flow separation over the leeward side of significant topography, and can be characterised in terms of the steepness of the slope and its alignment with the prevailing wind direction. This information may be applied to a Digital Elevation Model (DEM) which then identifies parts of the landscape that are sufficiently steep and lee-facing for flow separation to occur. It therefore identifies the parts of the landscape where ambient horizontal vorticity, which is a prerequisite for VLS occurrence, is likely to exist. We refer to this model as the wind-terrain filter.

\section{Slope scaling and DEM resolution}

The slope threshold for flow separation is approximately 20 degrees (Sharples et al. 2020), however as the resolution of the DEM decreases (i.e. coarsens), the slope distribution (and therefore the slope threshold) also decreases (Grohmann 2015). This is due to the smoothing of the DEM. The first step is to determine the slope threshold for the different DEMs.

\section{METHOD}

\subsection{Datasets}

The datasets used for this research were from the Shuttle Radar Topography Mission (SRTM) (Farr et al. 2007); the 1 second, 3 second-derived (Geoscience Australia 2010) and 9 second datsets with resolutions of approximately 30,90 , and 250 metres respectively.

\subsection{Filter}

Two filters are required for analysing VLS - a first-order differential of elevation (i.e. the slope). A first-order filter on its own would be sufficient if real topography reflected a hill such as that in Fig. 2 a. However, is not sufficient in rugged terrain which has 'broken' topography. Ridge lines and bluffs which adjoin VLS-prone slopes, are all part of the VLS-prone landscape. Unfortunately, these ridges are not identified by a first-order filter as this filter only captures slope greater than a certain threshold (but not the top of the ridge, which tends to have gentler slopes (Fig. 2 b)). Therefore, a second-order is needed to identify the leeward ridgelines (Fig. $2 \mathrm{c})$.

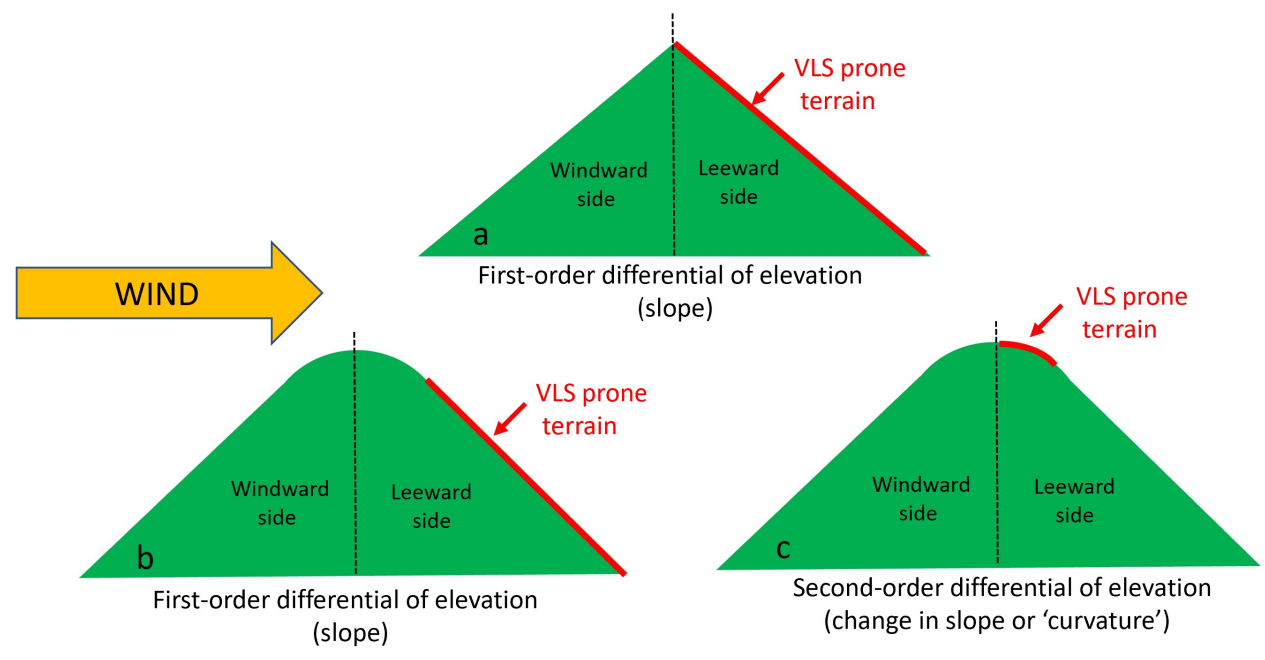

Figure 2. First-order VLS filter for a) an unbroken hill profile, and a simple ridge profile with b) a first-order filter, and c) a second-order filter. 
R.L. Badlan and J.J. Sharples, Spotfire Utilisation Project: Development of a mapping tool...

First-order filter. As described previously, VLS is dependent on the slope and the aspect of that slope to the prevailing wind. These conditions may be expressed formally as:

$$
\chi(\sigma, \delta)= \begin{cases}1 & \text { if } \mathrm{S} \geq \sigma \text { and }|\theta-\alpha| \leq \delta \\ 0 & \text { otherwise }\end{cases}
$$

where $S$ is the topographic slope, $\alpha$ is the topographic aspect, and $\theta$ is the direction the wind is blowing from. This is the opposite of the standard wind direction and is calculated by subtraction (if greater than or equal to $180^{\circ}$ ) or addition of $180^{\circ}$ from the the standard wind direction; therefore, a westerly wind has a direction of $90^{\circ} . \sigma$ and $\delta$ are the slope threshold and aspect discrepancy respectively. In summary, the first-order filter identifies areas of the landscape with lee-facing slopes where flow-separation is likely to occur (i.e., slope greater than $20^{\circ}$ ), however the slope threshold will depend on the resolution of the DEM being used (see 2.2).

Second-order filter. The second-order filter depends on the second order directional derivative of the surface (DEM) and the aspect:

$$
\phi(C, \delta)= \begin{cases}1 & \text { if } \mathrm{C}<0 \text { and }|\theta-\alpha| \leq \delta \\ 0 & \text { otherwise }\end{cases}
$$

where $C$ is the profile curvature, $\alpha$ is the topographic aspect and $\theta$ is the direction the wind is blowing from. The profile curvature tool in ArcGIS Pro is used to achieve this. The profile curvature is parallel to the slope, indicating maximum slope. This filter identifies areas of the landscape that are associated with ridge lines, whereas the first-order identifies slopes. Initially this filter is set to identify areas of negative curvature $(C<$ 0 ), which results in identifying typical ridge lines such as those shown in Fig. 2 b and c.

These two filters are then combined and have an extra processing step, whereby isolated pixels are removed, effectively removing 'noise' from the filter.

Slope Thresholds. To determine the slope threshold for each DEM, the slope function in ArcGIS Pro is employed. This function uses the algorithm described in Horn (1981). The aspect and curvature functions are also explained in this paper.

The slope threshold for each resolution (approximately $30 \mathrm{~m}, 90 \mathrm{~m}$, and $250 \mathrm{~m}$ ) is then calculated by looking at the distribution of slopes across a number of domains with various landforms. Figure 3 shows a density plot of the slopes across a domain located in an area encompassing the Brindabella ranges spanning NSW and western ACT (see Fig. 9 (Sharples et al. 2012)).

A series of calibrations were also run to determine the smallest aspect discrepancy that could be used but that still captured the relevant regions of the landscape.

\section{RESULTS}

\subsection{Slope Thresholds}

As the slope threshold used for the filter will be applied to all the filters created across Australia, the slope threshold that best represents all the domains analysed, was chosen. These domains had a variety of landforms, and while most contained rugged areas, some domains had mixed topography with flat regions as well as rolling hill landforms. After analysis (which is detailed further in Badlan (2021)), the chosen thresholds are $18^{\circ}, 15^{\circ}$, and $11^{\circ}$ for the $30 \mathrm{~m}, 90 \mathrm{~m}$, and $250 \mathrm{~m}$ respectively.

Previous work by Sharples et al. (2012) determined that the aspect discrepancy of $\pm 40^{\circ}$ (the angle between the wind and the aspect) best captured the VLS events.

\subsection{The static filter}

The version of the filter initially supplied is the static filter. These are produced using a uniform wind direction for each of the main 16 cardinal points (N, NNE, NE, ENE, E, ESE, SE, SSE, S, SSW, SW, WSW, W, WNW, NW, and NNW). The filters are produced for each of the following states: New South Wales, Queensland, South Australia, Tasmania, and Victoria. Each filter is supplied in a coarse resolution (based on a 250 metre resolution DEM) and an intermediate resolution (based on a 90 metre resolution DEM). 
R.L. Badlan and J.J. Sharples, Spotfire Utilisation Project: Development of a mapping tool...

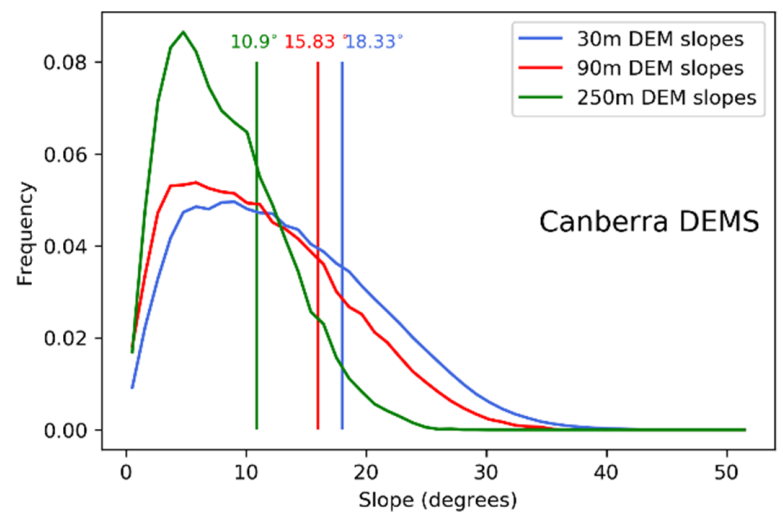

Figure 3. Slope distribution for a region in the Brindabella region near Canberra

\subsection{Bridger Hills, Montana}

To test the wind-terrain filter, a case study from Bozeman, Montana was chosen, as it was a textbook example of VLS. The case study is detailed in Bridger Foothills Fire Entrapment and Shelter Deployment (2020); a summary is given here.

\section{Background}

On Friday $4^{\text {th }}$ September 2020, lightning ignited a fire along the western side of Bridger Ridge, near Bozeman, Montana. This fire led to entrapment of three fire agency staff the next day following a change in wind direction.

\section{Application of the filter}

\section{Prior to the wind change}

Figure 4 shows the VLS wind-terrain filter for the wind conditions prior to the wind change that occurred. It is clear that there is a low risk of VLS, given the southerly wind. The dark blue polygon is the fire perimeter and the is a small regon of VLS risk in the north side of the fire. The fire crew were in the vicinity of the blue circle.

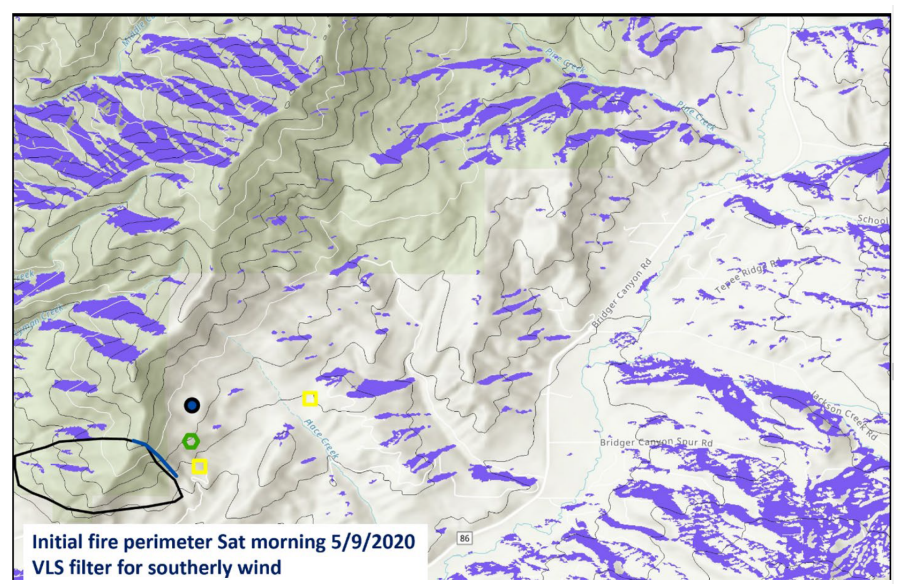

Figure 4. Wind-terrain filter for southerly wind direction. The fire crew were in the vicinity of the blue circle with dark outline. The purple areas indicate regions of VLS-prone land. The dark blue line is the initial fire perimeter (before the wind change on $5^{\text {th }}$ September ) supplied by the Montana Department of Natural Resources and Conservation. 


\section{After the wind change}

The forecast conditions for early afternoon (around $1330 \mathrm{~h}$ ) on Saturday $5^{\text {th }}$ were for the wind to shift to westerly, and increase in strength with gusts up to $50 \mathrm{~km} \mathrm{~h}^{-1}$ and a drop in relative humidity (6-11\%). The forecast temperature was $33-36^{\circ} \mathrm{C}$.

Application of the filter for the forecast wind highlights the areas of VLS risk for the afternoon (shown bt the purple regions). The blue polygon shows the fire perimeter before the forecast change, and the red polygon, the final perimeter. It is clear from Fig. 5 that the fire is likely to spread northwards along the ridgeline. This lateral spread suggests a strong change of mass spotting on the eastern side of Bridger Ridge.

If the terrain-induced airflow (yellow arrows in Fig. 5) is also considered when interpreting the filter, then there are two mechanisms driving the fire northwards; both VLS and the mass spotting and fire coalescence would effectively infill the eastern ridge area of Bridger Hills.

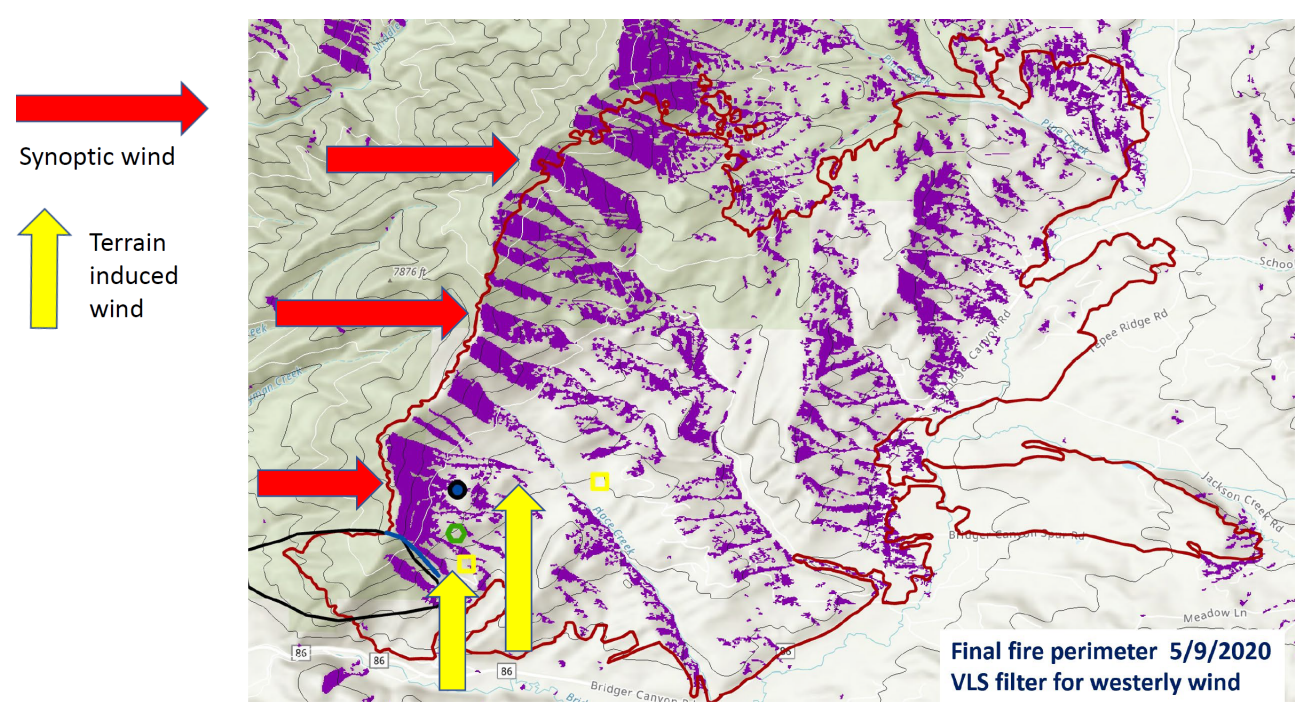

Figure 5. Wind-terrain filter for westerly wind direction. The dark blue line is the initial fire perimeter and the red line is the final perimeter as supplied by the Montana Department of Natural Resources and Conservation.

\section{CONCLUSIONS}

The Bridger Foothills scenario indicates how the fire spread could have reasonably been anticipated using this tool. When used as an interpretive device, along with other information such as the forecast wind, terraininfluences and current fire perimeter, it can indicate both the direction and the limit of spread during a given event. Perhaps more importantly, it can help quickly identify whether a fire is likely to erupt into a mass fire. It is recommended that this filter becomes a tool in the prediction of fire spread in order to identify which small fires are most likely to transition to larger or even extreme fires. In the most dire scenarios, these fires may then couple to the atmosphere and cause violent pyroconvection. By identifying these fires and depending on the time frame and accessibility to those areas, then either preventing their spread or early evacuation may be possible, thereby preventing entrapment.

Other case studies have been also been used to determine whether the filter captures VLS-prone areas associated with real fires. In all cases studied, locations where the lateral spread actually occurred is identified. When the resultant mass spotting and fire coalescence is also taken into account, the transition to extreme fire can be reasonably approximated. The static filters are currently being used by the fire agencies, however further refinements are planned.

\section{FURTHER WORK}

Currently, the filters have been developed (at $90 \mathrm{~m}$ and $250 \mathrm{~m}$ resolutions) for New South Wales, Queensland, South Australia, Tasmania and Victoria. It is intended to add more wind-terrain filters covering Western 
R.L. Badlan and J.J. Sharples, Spotfire Utilisation Project: Development of a mapping tool...

Australia, and to add $30 \mathrm{~m}$ resolution filters for all existing areas. A dynamic version of the filter is also being explored. This dynamic filter would use forecast wind data (such the Bureau of Meteorology wind forecasts or Wind Ninja) at the nearest gridpoint rather than a uniform wind that represents the synoptic wind. This would be more accurate, especially in areas with large or rugged landforms, whereby the airplow may be diverted, blocked or diverted due to the influence of the terrain. A range of extra cases where VLS occurred but is not identified may also be investigated to refine the filter further.

\section{ACKNOWLEDGEMENT}

The authors would like to acknowledge the Bushfire and Natural Hazards Cooperative Research Centre (now Natural Hazards Research Australia) for funding of this project. Digital Elevation Model (DEM) datasets courtesy of Geoscience Australia.

\section{REFERENCES}

Badlan, R. L., Sharples, J. J., Evans, J. P. \& McRae, R. H. (2021a), 'Factors influencing the development of violent pyroconvection. Part I: fire size and stability', International Journal of Wildland Fire 30, 484-497.

Badlan, R. L., Sharples, J. J., Evans, J. P. \& McRae, R. H. (2021b), 'Factors influencing the development of violent pyroconvection. Part II: fire geometry and intensity', International Journal of Wildland Fire 30, 498512.

Badlan, R.L. Sharples, J. (2021), Spotfire utilisation project: Implementation of the VLS filter: Final Report 2021., Technical report, Bushfire and Natural Hazards Cooperative Research Centre, Melbourne.

Bridger Foothills Fire Entrapment and Shelter Deployment (2020), Technical report, Montana Department of Natural Resources and Conservation, USDA Forest Sevice, Region 1/ Custer-Gallatin National Forest.

Dillon, H. (2015), 'Inquiry into fire at Wambelong Camp Ground, Warrumbungles National Park, New South Wales, January 2013', NSW Coroners Court.

Farr, T. G., Rosen, P. A., Caro, E., Crippen, R., Duren, R., Hensley, S., Kobrick, M., Paller, M., Rodriguez, E., Roth, L. et al. (2007), 'The shuttle radar topography mission', Reviews of geophysics $\mathbf{4 5}(2)$.

Geoscience Australia (2010), 3 second SRTM Digital Elevation Model (DEM) v01., Technical report, Geoscience Australia, Bioregional Assessment Source Dataset. Bioregional Assessment Source Dataset.

Grohmann, C. H. (2015), 'Effects of spatial resolution on slope and aspect derivation for regional-scale analysis', Computers \& Geosciences 77, 111-117.

Horn, B. K. (1981), 'Hill shading and the reflectance map', Proceedings of the IEEE 69(1), 14-47.

McRae, R. (2004), 'The breath of the dragon-observations of the January 2003 ACT bushfires', Proceedings of Bushfire 2004, Adelaide.

McRae, R. H., Sharples, J. J. \& Fromm, M. (2015), 'Linking local wildfire dynamics to pyrocb development', Natural Hazards and Earth System Sciences 15(3), 417-428.

Quill, R. \& Sharples, J. (2015), Dynamic development of the 2013 Aberfeldy fire, in '21st International Congress on modelling and Simulation', Gold Coast Australia, pp. 284-290.

Sharples, J. J., Cary, G. J., Fox-Hughes, P., Mooney, S., Evans, J. P., Fletcher, M.-S., Fromm, M., Grierson, P. F., McRae, R. \& Baker, P. (2016), 'Natural hazards in Australia: extreme bushfire', Climatic Change 139(1), 85-99.

Sharples, J. J., Hilton, J. E., Sullivan, A. L. \& Badlan, R. L. (2020), Fire coalescence and mass spot fire dynamics: experimentation, modelling and simulation - annual project report 2019-2020, Bushfire and Natural Hazards CRC, Melbourne.

Sharples, J. J., McRae, R. H. \& Wilkes, S. R. (2012), 'Wind-terrain effects on the propagation of wildfires in rugged terrain: fire channelling', International Journal of Wildland Fire 21(3), 282-296.

Simpson, C. C., Sharples, J. J. \& Evans, J. P. (2016), 'Sensitivity of atypical lateral fire spread to wind and slope', Geophysical Research Letters 43(4), 1744-1751.

Simpson, C., Sharples, J. \& Evans, J. (2014), 'Resolving vorticity-driven lateral fire spread using the WRF-Fire coupled atmosphere-fire numerical model', Natural Hazards and Earth System Sciences 14(9), 2359-2371.

Simpson, C., Sharples, J. \& Evans, J. (2015), WRF-Fire simulation of lateral fire spread in the Bendora fire on 18 January 2003, in 'MODSIM2015, 21st International Congress on Modelling and Simulation, eds T. Weber, M. McPhee, and R. Anderssen (Gold Coast, QLD: Modelling and Simulation Society of Australia and New Zealand)', pp. 305-311. 